\title{
THE RELATIONSHIP BETWEEN ARSENICAL POISONING AND YPERITIS.
}

\author{
Bт J. E. R. McDONAGH, F.R.C.S.
}

In cases of arsenical and mustard-gas poisoning, which have come before me, three points which are common to both stand out: (1) the delayed onset of symptoms of intoxication; (2) the fact that such symptoms may vanish and then reappear; (3) the frequency with which a bacterial infection complicates the worst cases. Points numbers (1) and (2) show that the drugs must become attached to certain cells in the body, and that they must undergo some chemical change. The fact that the symptoms of intoxication can recur, without more of the drug finding entrance, indicates that the drug so chemically changed is not readily excreted. This being the case suggests that the toxic action is physical in nature, and possibly catalytic. Relapses are more likely to occur in cases of arsenical and other metallic intoxications than in yperitis, but in both they can be caused by the introduction of such substances as alcohol, chloroform, ether, etc. The last-named drugs are well known for their power of depressing the oxidising process in corpore, by increasing the socalled "acidness" of the blood. At first sight, then, yperitis would appear to be caused by di-chlor-ethyl sulphide undergoing hydrolysis and producing hydrochloric acid, as in the following equation :

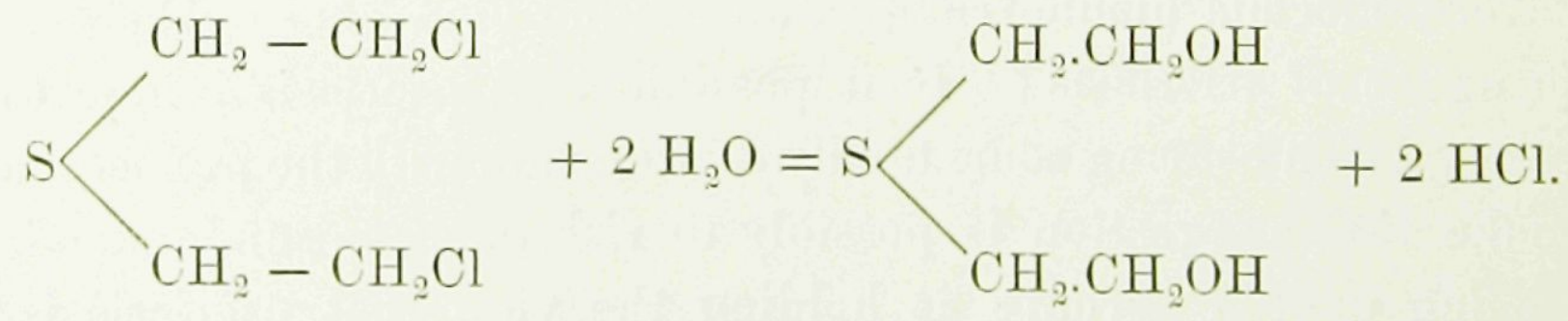

Di-chlor-ethyl sulphide readily hydrolyses, di-hydroxy-ethyl sulphide is an almost innocuous substance, sodium bicarbonate is not so good an antidote to yperitis as is a metal in a colloidal form, and a comparatively large quantity of hydrochloric acid may be injected 
intravenously with impunity; therefore, it would appear that the simple production of hydrochloric acid is not the main cause of yperitis. Di-chlor-ethyl sulphide becomes non-toxic if the chlorine atoms are replaced by hydrogen or hydroxyl, or if the two chlorine atoms become differently orientated, or if more chlorine atoms are introduced into the molecule, and, as the toxic action is maintained if the sulphur atom is replaced by either selenium or tellurium, two elements which belong to the same periodic group as sulphur, two assumptions may therefore be made: (1) that the element plays some part in the causation of the symptoms of intoxication; (2) that di-chlor-ethyl sulphide is readily adsorbed by the protein colloidal particles. For most of these details I am deeply indebted to $\mathrm{Mr}$. C. Perry, the Director of Chemical Inspection.

Merely upsetting the hydrogen ion concentration of the external phase or liquid part of the serum, which can be readily done by either hydrochloric acid or sodium hydrate, is not sufficient to upset the patient. Symptoms of intoxication appear to arise only when the internal phase or protein colloidal particles are deranged by colloids possessing either a negative or a positive electric charge, as I have proved by injecting rabbits intravenously with colloidal silicic acid and colloidal aluminium liydroxide respectively. The orientation of the mustard-gas molecule is such as to enable it to become adsorbed to the protein colloidal particles, the normal colloidal state of which it upsets: (1) by the formation of hydrochloric acid; (2) by the action of sulphur. As there is every reason to believe that the molecule of mustard-gas, once adsorbed, is no longer di-chlor-ethyl sulphide, it would be difficult to explain how the continued formation of hydrochloric acid could be kept up. As sulphur would always be present until completely excreted, and as sulphur can act as a catalyst, on theoretical grounds alone, it would be reasonable to infer that the main factor in the rtiology of yperitis was the element sulphur.

In the action of drugs in the body orientation of the compound is everything, as is proved by the facts: (1) that colloidal sulphur and di-para-di-amino-thio-benzene are useless in metallic poisoning, compared with di-ortho-di-amino-thio-benzene; (2) that colloidal arsenic and atoxyl cannot compare in the treatment of syphilis with di-oxy-di-amino-arseno-benzene.

VOL. XXXII. 
Consequently it follows that a ratio exists between the toxic and the therapeutic action of a drug and its power of becoming adsorbed to the protein colloidal particles. In metallic poisoning we know the element itself is the cause, for mercury, arsenic and lead as inorganic salts are capable of producing symptoms of intoxication, and furthermore, the same chain of symptoms may be produced by an inorganic salt of arsenic as by arseno-benzene. As some of the cases of arsenical poisoning following the administration of arseno-benzene have been particularly severe, the point has been raised whether it was the benzene which was the toxic agent. As the arseno-benzene molecule is no longer arseno-benzene when the symptoms of arsenical poisoning set in, and, as intramine, in spite of its being a thiobenzene, is a specific for such cases, provided it is prescribed before the patient is past recovering, it may reasonably be assumed that the arsenic in arseno-benzene and the sulphur in mustard-gas are the toxic factors in arsenical poisoning and yperitis respectively. As colloidal silicic acid neutralises the toxic effect of colloidal aluminium hydroxide and vice versâ, as intramine is a specific for the toxic symptoms produced by any metal, and as colloidal manganese will correct an overdose of intramine, and is more efficacious than sodium bicarbonate in yperitis, sufficient proof is at hand to state that the sulphur is the main cause of yperitis, and not the hydrochloric acid which results from the hydrolysis of dichlor-ethyl-sulphide.

The question now arises as to the mode of action of arsenic and other metals and of sulphur when they cause intoxication. Broadly speaking, metals act as oxidising agents and non-metals as reducing agents. For metals to form active oxygen a peroxide appears to be necessary, as in the following diagrammatic formula:

$$
\mathrm{R} \cdot \mathrm{Fe}(\mathrm{OH})_{2}+\mathrm{HO} \cdot \mathrm{OH}+\mathrm{H} \cdot \mathrm{OH}=\mathrm{R} \cdot \mathrm{Fe}(\mathrm{OH})_{3}+\mathrm{H}_{2} \mathrm{O}+\mathrm{OH} .
$$

The peroxide being destructible has to be continuously replaced, and this is done by sulphur, as in the following diagrammatic formula:

$$
\text { R.S.S.R. }+2 \mathrm{H} . \mathrm{OH}=\mathrm{R} . \mathrm{S}+\mathrm{R} . \mathrm{SH}+\mathrm{HO} \cdot \mathrm{OH}+\mathrm{H} .
$$

If too much metal is used it would appear to result in its own oxidation, the effect being to increase the "acidness" of the blood, as in the following diagrammatic formulæ: 


$$
\begin{gathered}
\text { R.Mn }(\mathrm{OH})_{2}+\mathrm{HO} . \mathrm{OH}+\mathrm{H} \cdot \mathrm{OH}=\mathrm{R} \cdot \mathrm{Mn}(\mathrm{OH})_{4}+\mathrm{H}_{2} \mathrm{O} \\
\text { R.Mn }(\mathrm{OH})_{4}=\text { R.Mn } \mathrm{O}(\mathrm{OH})_{2}+\mathrm{H}_{2} \mathrm{O}
\end{gathered}
$$

As sulphur forms the peroxide necessary for the metal to work upon, this appears to be the most reasonable solution at present for the action of intramine in metallic poisoning. Besides the peroxide, sulphur also forms hydrogen, and if it does so in excess it must also increase the "acidness" of the blood and cells. Why, then, is a metal an antidote for yperitis? Hydrogen converts the trivalent hydroxide form of the metal into its divalent or catalytic form as in the following formula :

$$
\text { R. } \mathrm{Mn}(\mathrm{OH})_{3}+\mathrm{H}=\mathrm{R} \cdot \mathrm{Mn}(\mathrm{OH})_{2}+\mathrm{H}_{2} \mathrm{O} .
$$

If a metal be employed in yperitis, the hydrogen is utilised by keeping the metal in that form in which it can produce the most active oxygen, the effect being to utilise and neutralise the factor actually causing the "acidness" of the blood, namely, hydrogen. In the hydrolysis of di-sulphide-protein, mercaptan-protein is formed. Owing to the affinity shown by mercaptan for oxygen, and still more so for iodine, one is able to explain (1) why the action of intramine is sometimes uneven; (2) why iodine prevents this and always increases its action. In the second of the two following formulæ-

$$
\begin{aligned}
& \text { (1) } 2 \text { R.SH }+\mathrm{O}=\text { R.S.S.R. }+\mathrm{H}_{2} \mathrm{O} \\
& \text { (2) } 2 \text { R.SH }+2 \mathrm{I}=\text { R.S.S.R. }+2 \mathrm{HI}
\end{aligned}
$$

it will be noted that iodine converts the mercaptan-protein back into the di-sulphide-protein-the form in which sulphur appears to act as a catalyst-thereby taking the place in the reducing action which hydrogen does in the oxidising action. In addition hydriodic acid is formed, which should have the same action as the hydrochloric acid which is formed on the hydrolysis of di-chlor-ethyl-sulphide. As iodine so materially increases the action of sulphur in spite of the hydriodic acid formed, it may reasonably be assumed that the formation of hydrochloric acid is not the cause of yperitis.

Thinking the action of intramine in the vulcanisation of rubber might throw some light on the subject in hand, I asked Mr. P. Schidrowitz to try it for me, which he very kindly did. Mr. Schidrowitz found (1) that intramine was an accelerator in the vulcanisation of rubber ; (2) that colloidal iodine in paraffin wax of a low melting point (to avoid the presence of water) did not increase its action. Mr. Schidrowitz 
was of the opinion that intramine acted as an accelerator by virtue of its amino-groups, and that it was activated or rendered more active by the sulphur. In the vulcanisation of rubber by sulphur, mercaptan does not appear to be formed, hence the probable reason why iodine did not add to the accelerating action of intramine. A point of some interest is the fact that methylene blue, which contains an atom of sulphur, retards vulcanisation. Methylene blue is particularly stable, and it does not liberate its sulphur atom in corpore, fur most, if not all, of the dye is excreted unchanged in the urine. The only change methylene blue is capable of undergoing in corpore is one of hydrogenation, which converts the dye into its leuco-base, a change which disturbs but little its molecular orientation. As a ratio exists between the rate of acceleration in the vulcanisation of rubber and the dissociation constant of the accelerator, we have ground for stating (1) that the first factor in intoxication is the adsorption between the intoxicant and the protein colloidal particles; (2) that the second factor is the dissociation of the intoxicant; (3) that the third factor is the catalytic action of the element liberated from the intoxicant by this dissociation and adsorbed by the protein colloidal particles.

Going back to mercaptan for a moment, it is of interest to note that the odour of urine after the ingestion of asparagus is due thereto. It is probable that mercaptan is the cause of the rheumatism which asparagus is apt to cause, because the best treatment for it is colloidal iodine, and because the same symptoms are produced when over-doses of intramine are prescribed. As rheumatism is also a common symptom of metallic intoxication, it seems reasonable to infer that both metals and non-metals produce intoxication by interfering with the oxygen supply of the tissues.

The next step was to prove that both selenium and tellurium have a reducing action in corpore. For this purpose Mr. J. Patterson kindly prepared for me colloidal emulsions of both these elements. The therapeutic action of colloidal selenium was the same as that of colloidal tellurium, and both behaved similarly to intramine except that they were not so active. The trials were undertaken in cases of mercurial stomatitis, arsenical jaundice, gonorrhœal rheumatism, Acne vulgaris and chronic seborrhœic eczema. Like intramine, both colloids aggravated cases of acute urethritis and furunculosis, an action which 
was at once counteracted by colloidal manganese. Colloidal selenium and colloidal tellurium are more active than colloidal sulphur, and they stand between colloidal sulphur and iutramine, as arseno-phenylglycine does between atoxyl and arseno-benzene. They are more active than sulphur, because their atomic weights are higher (sulphur $32 \cdot 07$, selenium $79 \cdot 2$, tellurium $127 \cdot 5$ ) and less active than intramine, because they contain no amino-groups-the groups which play such an important rôle in the adsorption between a drug and the protein colloidal particles. This explains why arseno-benzene is more active than mercury in the treatment of syphilis, and shows that the action of mercury is in a large part due to its high atomic weight. All who have treated many cases of syphilis with arseno-benzene must have noticed how frequently other dormant infections were aroused, such as furunculosis, Acne vulgaris, gonococcal urethritis, with epididymitis complicating it, throat and pulmonary infections. When a patient is poisoned with arseno-benzene and develops arsenical dermatitis, the picture is frequently complicated by multiple boils, carbuncles and abscesses, aud, should death result, it is nearly always due to a broncho-pneumonia, which may be of septic, influenzal or pneumococcic origin. Therefore it would only be natural to expect an acute coli infection in cases which had succumbed to arsenical hepatitis. Staphylococcic and streptococcic skin affections were common complications of yperitis when the skin was the main tissue damaged. When the pulmonary tract was the part most attacked, either septic, influenzal or pneumococcic infections were liable to carry off the patient.* This shows (1) that metallic and non-metallic intoxication depress the resistance of the patient and so render him more liable to infections which normally he was able to keep in check; (2) that drugs have not a direct action upon parasites, but only an indirect one through the host's protective substance. We may also learn from these observations (1) that the chemo-therapeutic programme is incomplete without a metal and a non-metal; (2) that the treatment of patients must be individual, because it is easier to destroy the resistance of one patient than that of another.

* A point of considerable clinical importance in this connection is that Vincent's angina, when it develops de novo, rapidly responds to ar'seno-benzene, but when it is caused by arsenic and mersury, intramine is the only drug which will rapidly cause its disappearance. 


\section{Conclusions.}

(1) That arsenic is the cause of arseno-benzene poisoning, and sulphur of mustard-gas poisoning.

(2) That arsenic and sulphur act as catalysts, which fact prevents their ready excretion and induces the recurrence of the symptoms of intoxication.

(3) That metals and non-metals are antidotes one for the other.

(4) That metals and non-metals act therapeutically through the host's resisting substance, which latter they destroy if prescribed in over-dose, thereby enabling other organisms which are normally kept in check to multiply until they kill the patient. 
This document is a scanned copy of a printed document. No warranty is given about the accuracy of the copy. Users should refer to the original published version of the material. 